\title{
Conformism in the food processing techniques of white-faced capuchin monkeys (Cebus capucinus)
}

\author{
Susan Perry
}

Received: 10 September 2008 / Revised: 24 February 2009 / Accepted: 29 April 2009 / Published online: 20 May 2009

(c) The Author(s) 2009. This article is published with open access at Springerlink.com

\begin{abstract}
Researchers of "culture" have long been interested in the role of social learning in establishing patterns of behavioral variation in wild animals, but very few studies examine this issue using a developmental approach. This 7-year study examines the acquisition of techniques used to process Luehea candida fruits in a wild population of white-faced capuchin monkeys, Cebus capucinus, residing in and near Lomas Barbudal Biological Reserve, Costa Rica. The two techniques for extracting seeds (pounding or scrubbing) were approximately equal in efficiency, and subjects experimented with both techniques before settling on one technique-typically the one they most frequently observed. In a sample of 106 subjects that had already settled on a preferred technique, the females adopted the maternal technique significantly more often than expected by chance, but the males did not. Using a longitudinal approach, I examined the acquisition of Luehea processing techniques during the first 5 years of life. Regression analysis revealed that the technique most frequently observed (measured as proportion of Luehea processing bouts observed that used pounding as opposed to scrubbing) significantly predicted the technique adopted by female observers, particularly in the second year of life; the
\end{abstract}

Electronic supplementary material The online version of this article (doi:10.1007/s10071-009-0230-3) contains supplementary material, which is available to authorized users.

S. Perry $(\square)$

Department of Anthropology, Behavior, Evolution and Culture Program,

University of California-Los Angeles, 341 Haines Hall,

375 Portola Plaza, Los Angeles, CA 90095-1553, USA

e-mail: sperry@anthro.ucla.edu amount of impact of the observed technique on the practiced technique was somewhat less significant for male observers. These results held true for (a) observations of maternal technique only, (b) observations of technique used by all individuals other than the mother, and (c) observations of maternal and non-maternal techniques combined.

Keywords Social influence $\cdot$ Cebus capucinus $\cdot$ Food processing $\cdot$ Capuchins $\cdot$ Development

\section{Introduction}

Debate on a central anthropological issue, the origin and function of human cultural capacities (Richerson and Boyd 2005; Laland and Galef 2009; Perry 2006) has been powerfully affected in the past decade by the discovery of between-population differences in food processing techniques among wild non-human primates such as chimpanzees (Whiten et al. 1999), orangutans (van Schaik et al. 2003a), capuchins (Panger et al. 2002) and macaques (reviewed in Perry and Manson 2003). However, it remains unclear to what extent these differences are driven by social learning processes generally, and by copying, i.e., replicating an observed behavior, in particular.

Social learning, in its broadest sense, is defined as changes in the behavior of one individual that result at least in part from (a) attending to the behavior of another individual, (b) accompanying another individual so that the learner is exposed to new experiences, or even (c) encountering physical traces of others' activities that alter the discoverer's behavior (Box 1984; Fragaszy and Perry 2003). Such a definition includes both the acquisition of new knowledge or skills as a result of observing others, and also social influence biasing individuals toward the use of 
behaviors already in their repertoires. Most research on cultural transmission in non-human primates has focused on the role of social influence in the spread of recent innovations throughout populations. But another potentially important social process affecting between-group differences in behavior is conformism - the tendency for individuals to preferentially exhibit behavioral alternatives that they witness most frequently in their peers, or to exhibit the behaviors that are performed by peers who are considered most prestigious or successful, or those peers with whom they have the highest quality social relationships (however that might be defined). Conformism can involve the adoption of new behaviors, but it can also involve an acquired preference of the use of behaviors that are already in an individual's behavioral repertoire and/or the suppression of some other behavior formerly used in a particular context.

Due to the difficulty in measuring social influence in the wild, researchers who want to explain between-population differences in the behavior of wild primates have turned to captive animals to investigate the mechanisms of social learning that are likely to exist in the wild. Evidence from captive great apes (Whiten et al. 2005), captive brown capuchins (Dindo et al. 2007; Fredman and Whiten 2008; Bonnie and de Waal 2007; de Waal and Bonnie 2009; Fragaszy et al. 2004) and rehabilitant orangutans (Russon et al. 2007; Russon 2003) shows that, given frequent opportunities to observe model individuals with whom they have tolerant relationships, individuals can be induced to copy objectmanipulation techniques that they have observed, thereby producing conformity biases and/or the maintenance of multiple traditions for solving the same foraging problem However, captive animals can sometimes be induced to express behaviors and exhibit problem-solving skills that are rarely expressed in the wild (Snowdon 2001; Kummer 1995), and so it is not necessarily safe to assume that phenomena documented in captivity also occur in the wild.

Documenting social learning in the wild is methodologically difficult; no one method can produce air-tight evidence, and it is therefore necessary to use multiple approaches to build a convincing case. Arguments for a central role of social learning in explaining non-human primate behavioral variation have been based largely on the "geographic" or "group contrasts method" (Whiten et al. 1999; van Schaik et al. 2003a; Fragaszy and Perry 2003), in which researchers (1) consider genetic and ecological explanations for observed geographic patterns of behavioral variation and (2) infer, for those behavior patterns for which such explanations are rejected, that the behavioral variation results from social learning. Of course, it is impossible to completely reject genetic and ecological explanations as possible influences on the acquisition of behavioral traits, especially for ecologically functional behavior, and it is likely that both factors play at least a minor role in explaining the patterning of variation in most if not all of the behavior patterns termed "traditions". Furthermore, it is to be expected that if a trait has high adaptive value (e.g. it enhances foraging efficiency), it should spread and replace less efficient variants until the trait is homogeneous within the population. Even for those behavior patterns that are influenced by genetic or ecological factors, there can still be a role of social learning that exerts an important independent influence on the acquisition of traits and the patterning of a trait's distribution within and between populations (Fragaszy and Perry 2003; Byrne 2007). For these reasons, the "group contrasts" method should be complemented by methods that seek other sorts of evidence for social learning.

Byrne (2007; Corp and Byrne 2002) has argued in favor of examining the acquisition of complexly structured foraging tasks that are homogeneous in a population, on the grounds that it is implausible that such complex behavior patterns could become uniform in a population without social influence. While this is likely to be true, it is hard to know exactly how complex a task has to be in order to be too complex for most typical members of the species to discover a behavioral sequence via individual trial-and-error learning. For example, the construction of leaf tools in New Caledonian crows was assumed to be too complex a task to acquire without social influence until experiments showed that tools of surprising complexity could be produced by individuals reared in isolation (Kenward et al. 2006). Likewise, two captive-born chimpanzees with no prior exposure to the rough bristly leaves used by wild chimpanzees for expelling intestinal parasites spontaneously folded such leaves upon their first encounter with them and swallowed them whole, just like their wild counterparts (Huffman and Hirata 2004). Another difficulty with Byrne's approach is that the homogeneity in the technique used makes it hard for the researcher to assess the amount of social influence that occurs, because all individuals ultimately acquire the same behavior patterns regardless of whom they have been watching.

In those rare and fortuitous cases in which there are multiple techniques that are common within a population (such as the capuchin Luehea processing described later in this paper, for which two techniques are approximately equally efficient), one productive research tactic is to compare within-group association patterns with patterns of technique distribution to see whether those dyads that spend more time together are also more likely to share the same techniques. Such an approach has been used by capuchin researchers (e.g. Panger et al. 2002; Perry and Ordoñez Jiménez 2006; O'Malley and Fedigan 2005) and has confirmed that dyads spending more time together are more likely to share techniques, though these results do not always attain statistical significance. Situations such as 
these are natural analogs to the "two-action" experimental methodology used to investigate imitation in captive situations (Fragaszy and Perry 2003; Whiten et al. 2005).

The problem with cross-sectional approaches such as these is that they do not necessarily capture the association patterns at the time when they are influencing skill acquisition, because social dynamics may change over the lifespan, and some individuals migrate. If skills are acquired early in life, then it is the social exposure during the skill acquisition phase-typically during the infant and juvenile phase, the precise period depending on the nature of the task-that is critical (Russon 2003; Perry 2009). Association patterns during adulthood may still provide fairly accurate representations of important relationships during the juvenile period for the philopatric sex, but certainly will not do so for the dispersing sex. A longitudinal developmental approach that measures social exposure over the time period when skills are being acquired will provide more meaningful results.

Longitudinal studies are rare because of the high cost and time commitment necessary to execute them. A multiyear study of the Gombe chimpanzees (Lonsdorf et al. 2004) showed that three immature female chimpanzees conformed to details of their mothers' termite tool-using technique, whereas three immature males did not do so. Case studies of the acquisition of feeding techniques in rehabilitant orangutans have also yielded promising results suggesting a strong role of social influence (Russon 2003). In this paper, I analyze the largest developmental data set thus far collected in a wild primate population, with the aim of investigating the role of social influence on food processing techniques in white-faced capuchin monkeys.

\section{Methodological procedures}

\section{Subjects}

The study was conducted on a wild, habituated population of white-faced capuchins monkeys (Cebus capucinus) residing in or near Lomas Barbudal Biological Reserve, in Guanacaste Province, Costa Rica. I have studied this population since 1990, and kinship relations are known for virtually all members of the study groups (Perry and Manson 2008; Muniz et al. 2006). The monkeys in this study resided in three social groups (AA, RR, and FF), though by the end of the study in 2007, AA group had fissioned once (producing FL group) and RR group had fissioned twice (producing RR2 and RR3 groups, see genealogies in S1 in the online supplement). The study groups all occupied forest that was essentially identical ecologically, and the groups had broadly overlapping home ranges, so that individuals of adjacent groups frequently visited the same
Luehea trees, though never at the same time. Monkeys within the same social group forage as a fairly cohesive unit, visiting the same Luehea trees at roughly the same time. White-faced capuchins live in multi-male, multifemale groups ranging in size from 5 to 38 individuals in this population. At Lomas Barbudal, females remain with their female kin (Perry and Manson 2008; Muniz et al. 2006), whereas males first disperse at a median age of 7 years (range 5-11). Females at Lomas Barbudal give birth for the first time at a median age of 6 years. Male reproductive maturity is harder to assess and is more variable, but males reach adult size at $8-10$ years.

Because the sons of the primary breeding male in one group often become the primary breeding male in adjacent groups (Perry and Manson 2008), there is no reason to expect significant genetic diversity between groups occupying adjacent/overlapping home ranges, as these groups do.

\section{Foraging task}

Luehea candida fruits are woody capsules containing many tiny, nutritious, wind-dispersed seeds (see Fig. 1). As the fruits ripen over a period of several months, five "seams" slowly open to release the seeds from the cracks. By pounding or scrubbing the fruits against a rough substrate, foragers can loosen the seeds from their point of attachment deep in the cracks so that they fall out or can be more easily plucked from the tip of the fruit. Pounding is defined as the repeated striking of the fruit against a substrate, whereas scrubbing is defined as repeatedly moving the fruit back and forth while it is firmly in contact with a rough surface. Luehea fruits are an important part of the capuchin diet, comprising $4.4 \%$ of foraging time over the course of a year, and $15.4 \%$ of all foraging time during the peak fruiting season (Perry and Ordoñez Jiménez 2006). Fruits may be present on the tree from November to August, but the peak season is typically January-May. There was no evident variation in the quality of Luehea fruits throughout the study site, and both processing techniques were practiced in all portions of each group's home range. One to three groups were followed each day, with up to four researchers per group. Luehea trees average $10 \mathrm{~m}$ in crown diameter and $15 \mathrm{~m}$ in height, and typically there are just 2-3 monkeys foraging in a tree simultaneously.

\section{Data collection}

The data collection protocol during Luehea candida foraging was as follows: My field assistants and I rotated through the monkeys feeding on Luehea, narrating detailed food processing observations onto microcassette recorders from the time a monkey began processing a fruit. When the fruit was dropped, the researcher switched to a new focal 


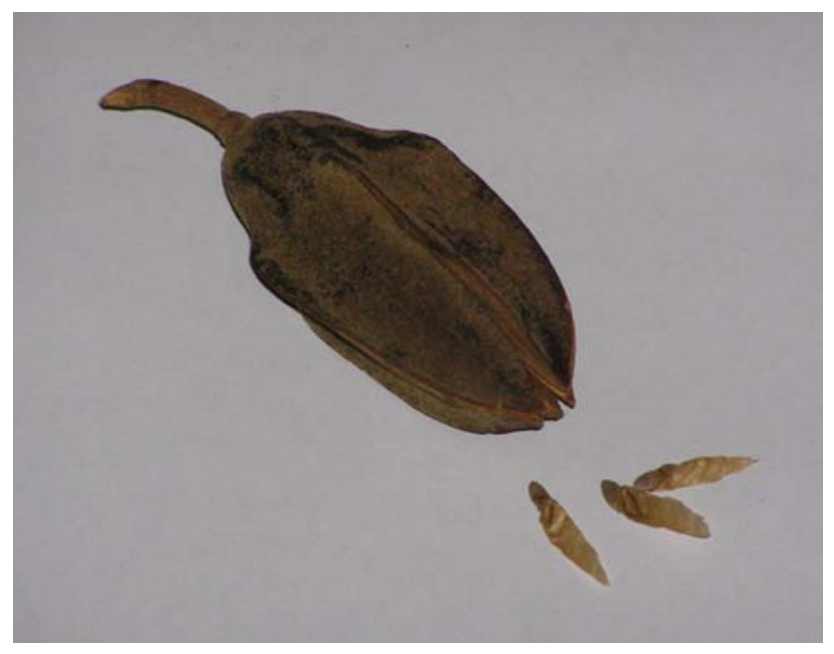

Fig. 1 Photograph of a Luehea candida fruit and some of its seeds, which are lodged deep in the cracks prior to processing

animal, waited until it began processing a new fruit, and continued recording the data until that fruit was dropped. During each sampling period, researchers noted (1) the focal monkey's processing techniques, (2) the identities of all other monkeys foraging on Luehea within ten body lengths $(400 \mathrm{~cm})$ of the focal animal, and (3) all instances in which the focal monkey's gaze was oriented toward a neighbor foraging within $400 \mathrm{~cm}$ of the focal (and the identity of that neighbor). All individuals of all age-sex classes were included in this data collection protocol. Tallies of data collected were maintained at the project headquarters so that under-sampled individuals could be given top priority for data collection. We attempted to sample all individuals evenly, but this was not always possible, because some monkeys forage on Luehea more than others.

In all statistical analyses, the term "years" refer to "developmental years," i.e., the number of Luehea seasons that the developing monkey has experienced, so that if an individual was born in the middle or end of Luehea season and hence had not yet begun leaving the mother's back prior to the end of the fruiting period, year 1 for that individual would be the year including the following Luehea season. Births are seasonal, with $69 \%$ of births occurring toward the end of the fruiting season, between April and July; the median birthdate is in May, the last month during which Luehea is typically a common item in the diet.

An additional method for assessing possible sex differences in visual attention to foragers was used, in case the small sample size of gazing events in the Luehea data set was preventing a significant effect from appearing. The data for this additional analysis was drawn from the broader developmental study, in which approximately 30 10-min focal follows are collected each month on each focal animal, and it evaluated visual attention to nearby monkeys foraging on any food, not just Luehea. Whenever focal individuals were within five body lengths $(200 \mathrm{~cm})$ of a foraging individual during 10-min focal follows, we noted whether the focal monkey visually attended to the forager. The terms "gazing," "looking," and "visually attending" are used interchangeably and are defined as orienting the head and eyes toward a particular target for a second or more. "Ignoring" is defined as not orienting the head and eyes toward a particular individual while it is foraging. To be included in this analysis, the following criteria were used: (a) the focal individual had to have contributed enough observations to be part of the Luehea processing developmental analysis (see "Statistical procedures"), (b) there had to be at least 25 observations for which the response (looking at or ignoring a neighbor foraging within $<200 \mathrm{~cm}$ ) was noted per 3-month block of time, and (c) the overall quality of data had to be high enough that the focal's responses to others' foraging efforts were clearly noted at least $75 \%$ of the time for that period. After these criteria were applied, the remaining data set consisted of 4022 hours of focal observation on 27 subjects.

Proximity data were taken from group scans (for individuals who were part of the Luehea processing study but not the broader developmental study) and instantaneous point samples collected at 2.5-min intervals during focal follows during Luehea season (for those subjects who were part of both studies). An average of 885 scans per monkey/year (range 208-2,092, SD 503) was used to calculate time spent within $<40 \mathrm{~cm}$ of the mother or time spent alone (i.e., with no other monkey within $<400 \mathrm{~cm}$ ). Instantaneous point samples from focal data for a sample of 25 monkeys (11 males and 14 females) were used to calculate this same information for monkeys aged 6-9 months.

It was impossible to assess the relative efficiency of the two processing techniques (scrubbing vs. pounding) from naturalistic observations, so the relative efficiency of the techniques was measured in the following way: 48 fruits were collected, and pairs of fruits were matched as closely as possible (by me and a field assistant) for the degree to which the cracks were open and the number of seeds visible inside. One of each pair was put in a separate pile. Then I applied $10 \mathrm{~s}$ of pounding to each fruit in one pile, and $10 \mathrm{~s}$ of scrubbing to the other pile. The number of seeds per fruit was calculated for each technique. Of course, I am not identical to a monkey in terms of hand size and strength, but I did my best to hold the fruits identically and to use the same amount of pressure, matching the sound of the pounding and scrubbing to that produced when the monkeys perform these actions at close range.

\section{Statistical procedures}

For each individual in the sample, I calculated the "proportion of pounding" (i.e., the number of fruits that was 
pounded, divided by the sum total of fruits that were pounded and fruits that were scrubbed); this is termed the "practiced technique". To measure the social exposure to pounding versus scrubbing (i.e., the "observed technique"), I performed the following calculations for each focal individual: (a) I listed all individuals who processed Luehea within ten body lengths of the focal, (b) I calculated "proportion of pounding" as described above for each foraging neighbor, (c) I calculated a pounding exposure score for each neighbor by multiplying the "proportion of pounding" by the number of samples in which the neighbor was in proximity to the focal animal, and (d) I calculated the total pounding exposure score for each focal individual as the sum of pounding exposure scores over all neighbors divided by the total number of foraging events that the focal could have witnessed. I summed all of these scores and divided that number by the total number of foraging events witnessed for any neighbor. These scores provide an estimate of each focal animal's relative exposure to pounding versus scrubbing by neighbors. These scores were calculated separately for each year of development for each individual.

To assess the effects of observation opportunities on practiced technique for various years of development, I used a Poisson regression model with the standard errors adjusted for within-subject correlation. Only those subject/ years in which there were at least ten fruits processed by the focal monkey and also ten social observation opportunities were retained in the sample, to ensure reliability of measurement. The resulting sample included 79 cases from 48 subjects ( 21 females and 27 males; 24 subjects contributed data to just 1 year, 17 to 2 years, and 7 to 3 years; none contributed to all 5 years). One female was dropped from the sample for the analysis of non-maternal influence due to lack of observation opportunity, and a male was dropped from the sample for analysis of maternal influence because his mother died before that season began. The regression analysis was performed with and without three male orphan outliers (NB, UG, and WM in the data set presented in S2 of the online supplement), because absence of the mother might reasonably be assumed to affect their social learning opportunities; exclusion of these individuals strongly affected the results, making males seem more similar to the females. In the regression analysis, a Poisson model was used because the outcome variable, proportion of pounding, is a rate measure derived from pounding counts (i.e., number of fruits pounded, divided by the sum of number of fruits pounded plus number of fruits scrubbed). The main predictor variable was "observed technique". Sex was also an independent variable, and developmental years were control variables. The model was run using three alternative measures of the observed technique: one that included observations of all monkeys, one taking into account only techniques used by the mother, and the third incorporating only observations of monkeys other than the mother.

The results in Table 2 are derived from the regression model in Table 1. Basically, the coefficients were exponentiated to produce the expected change in rate of pounding for one unit of change in the observed technique. For example, the coefficient 1.916 (for the OT in column 1 of Table 1), divided by 100 and then exponentiated, produces a coefficient of 1.0193 , which means that there is a $1.93 \%$ increase in proportion of pounding for a $1 \%$ increase in observed technique for males in year 1 . For details on the interpretation of Poisson models, see Long and Freese (2006). The word "impact" is sometimes used in the text to refer to the predictive power of the observed technique for the practiced technique in the regression model, but this does not necessarily imply biological causality.

Resampling statistics were used to make comparisons between the efficiency of pounding versus scrubbing, and also to compare males to females with regard to the amount of (a) time spent within $40 \mathrm{~cm}$ of the mother, (b) time spent alone, (c) attentiveness to monkeys foraging on Luehea, and (d) attentiveness to monkeys foraging on any food within $<200 \mathrm{~cm}$. For each analysis, a distribution was generated by shuffling, without replacement, the values from the two compared categories within and between categories, and then calculating the difference between the category means in these resampled data sets. This process was repeated 10,000 times. The probability of obtaining the observed difference, or a more extreme difference, between means is then regarded as the $P$ value. For example, if only five values in the set of 10,000 differences between the means of the categories in the resampled data set were equal to or more extreme than the observed difference in means, the $P$ value would be 0.0005 for a one-tailed test, or 0.001 for a two-tailed test.

\section{Results}

Relative efficiency of the two techniques

Scrubbing and pounding are equally efficient techniques (pounding, mean 7.8 seeds/10 s processing, SD 9.6; scrubbing mean 5.8 seeds $/ 10 \mathrm{~s}$, SD 6.2 ; resampling technique (see "Statistical procedures"), $P=0.40$ ).

\section{Distribution of techniques across the study population}

There was considerable between-group variation in the frequencies of pounding versus scrubbing among adults females (i.e., the philopatric sex) (Fig. 2). See the online supplementary information (S1) for genealogies showing the final primary technique for each natal group member. 
Table 1 Poisson regression models showing the impact of observed technique (OT) of various types (see top row), developmental year and sex on practiced technique

\begin{tabular}{|c|c|c|c|c|c|c|c|c|c|c|c|c|}
\hline \multirow[t]{2}{*}{$\begin{array}{l}\text { Predictor } \\
\text { variables }\end{array}$} & \multicolumn{2}{|c|}{$\begin{array}{l}\text { All influence } \\
\text { no orphans }\end{array}$} & \multicolumn{2}{|c|}{$\begin{array}{l}\text { All influence } \\
\text { with orphans }\end{array}$} & \multicolumn{2}{|c|}{$\begin{array}{l}\text { Maternal, } \\
\text { no orphans }\end{array}$} & \multicolumn{2}{|c|}{$\begin{array}{l}\text { Maternal } \\
\text { with orphans }\end{array}$} & \multicolumn{2}{|c|}{$\begin{array}{l}\text { Non-maternal } \\
\text { No orphans }\end{array}$} & \multicolumn{2}{|c|}{$\begin{array}{l}\text { Non-maternal } \\
\text { with orphans }\end{array}$} \\
\hline & Coef. & $\begin{array}{l}\text { Robust } \\
\text { SE }\end{array}$ & Coef. & $\begin{array}{l}\text { Robust } \\
\text { SE }\end{array}$ & Coef. & $\begin{array}{l}\text { Robust } \\
\text { SE }\end{array}$ & Coef. & $\begin{array}{l}\text { Robust } \\
\text { SE }\end{array}$ & Coef. & $\begin{array}{l}\text { Robust } \\
\text { SE }\end{array}$ & Coef. & $\begin{array}{l}\text { Robust } \\
\text { SE }\end{array}$ \\
\hline Year 2 & -0.515 & 1.164 & -0.468 & 1.261 & -0.881 & 0.886 & -0.728 & 0.875 & -0.582 & 1.243 & -0.582 & 1.243 \\
\hline Year 3 & 0.476 & 0.519 & 1.616 & 0.725 & 0.145 & 0.798 & 0.291 & 0.785 & 0.404 & 0.556 & 0.404 & 0.556 \\
\hline Year 4 & 1.202 & 0.593 & 1.345 & 0.559 & 0.301 & 0.647 & 0.477 & 0.606 & 1.088 & 0.635 & 1.088 & 0.635 \\
\hline Year 5 & 1.480 & 0.572 & 1.752 & 0.576 & 0.393 & 0.659 & 0.559 & 0.619 & 1.385 & 0.592 & 1.385 & 0.592 \\
\hline OT & 1.916 & 0.658 & 1.672 & 0.530 & 0.550 & 0.725 & 0.664 & 0.680 & 1.794 & 0.678 & 1.794 & 0.678 \\
\hline Year $2 \times \mathrm{OT}$ & 0.552 & 1.339 & 0.423 & 1.461 & 0.783 & 0.934 & 0.521 & 0.957 & 0.626 & 1.430 & 0.626 & 1.430 \\
\hline Year $3 \times$ OT & -0.291 & 0.617 & -2.172 & 1.016 & -0.186 & 0.860 & -0.690 & 0.900 & -0.178 & 0.662 & -0.178 & 0.662 \\
\hline Year $4 \times$ OT & -1.283 & 0.743 & -1.502 & 0.697 & -0.377 & 0.697 & -0.652 & 0.675 & -1.137 & 0.800 & -1.137 & 0.800 \\
\hline Year $5 \times \mathrm{OT}$ & -1.346 & 0.720 & -1.966 & 0.795 & -0.371 & 0.719 & -0.762 & 0.721 & -1.223 & 0.743 & -1.223 & 0.743 \\
\hline Female & -1.194 & 0.439 & -1.643 & 0.521 & -1.557 & 0.531 & -1.574 & 0.545 & -1.183 & 0.464 & -1.183 & 0.464 \\
\hline Female $\times$ OT & 1.308 & 0.542 & 2.166 & 0.718 & 1.485 & 0.538 & 1.757 & 0.579 & 1.302 & 0.592 & 1.302 & 0.592 \\
\hline Constant & -1.757 & 0.546 & -1.655 & 0.487 & -0.527 & 0.670 & -0.693 & 0.632 & -1.662 & 0.567 & -1.662 & 0.567 \\
\hline
\end{tabular}

Because males migrate in, bringing the techniques acquired in their natal groups, all groups include some scrubbers and some pounders who can serve as models for immature capuchins (note that migrant males are not depicted in Fig. 2 or S1). Eighty-one percent of all males were pounders, whereas $68 \%$ of females were pounders.

\section{Developmental trajectory}

During their first Luehea season, infants picked seeds from the ends of Luehea fruits but only attempted to extract the seeds by pounding or scrubbing in $29.9 \%$ of their handling attempts on average (SD 27.2\%, N=23 monkeys with ten or more Luehea foraging observations during the first year) and attempted no form of processing in $63 \%$ of handling attempts (SD 27.0\%). During year 1 and particularly in year 2 , infants tried a wide variety of techniques, including in most cases both pounding and scrubbing and sometimes

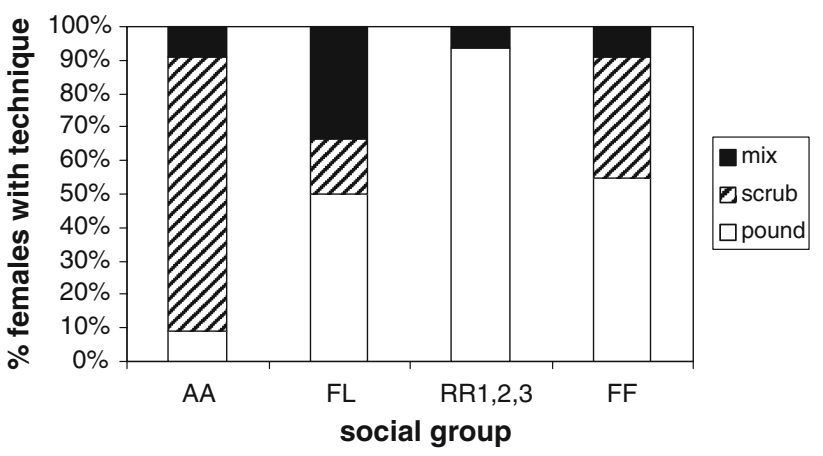

Fig. 2 Percentage of all adult females in each social group exhibiting each technique. FL is an offshoot of AA group. The fission products of $\mathrm{RR}$ group are lumped together since there was homogeneity among these females a pound-scrub combination, but also many inefficient actions such as juggling, tapping, dragging, slapping, rolling, spinning, twirling, shaking, scratching, bouncing on the fruit, and flailing it. During years 3-5, individuals eliminated inefficient variants, and generally settled on just one technique (pounding or scrubbing) by the time they reached age 5 (see S2), though even older animals did on rare occasion experiment with a second technique. In a sample of 10-20 observations of Luehea foraging it was typical for monkeys in their 1st or 2nd developmental years to employ about four different techniques. Over the course of the next 3 years of development, the range of techniques per monkey for a comparable sample of events dwindled from about 2-3 different techniques to one or two techniques, and if a second technique was sometimes employed in these older animals it was usually either pounding or scrubbing rather than an ineffective variant. The mean number of techniques employed per monkey for each year declined in the following way: year 1 , mean $4.0, \operatorname{SD} 1.1, N=6$; year 2, mean 3.9, SD 2.4, $N=19$; year 3, mean 2.6, SD 1.6, $N=30$; year 4 mean 2.6, SD $1.7, N=20$; year 5 , mean 2.2 , SD $1.4, N=17$.

By the age of 6-9 months, white-faced capuchins spend an average of only $9.7 \%$ (SD $4.1, N=25$ ) of their time within $40 \mathrm{~cm}$ of their mothers, but still spend an average of $89.5 \%$ (SD 3.8, $N=25$ ) of their time within $400 \mathrm{~cm}$ of at least one other monkey; so it seems possible that individuals other than the mother might be influential even at an early age. Hypothesized non-maternal social influences on food processing technique acquisition include alloparents, peers, and eventually all group members. Table 2 , which is based on the regression model detailed in Table 1, shows the impact of observed technique on the Luehea-processing 
Table 2 Impact of observed technique on the proportion of pounding, by year and sex

\begin{tabular}{|c|c|c|c|c|c|c|}
\hline & Year 1 & Year 2 & Year 3 & Year 4 & Year 5 & Average \\
\hline \multicolumn{7}{|c|}{ Independent variable: observed techniques (maternal and non-maternal combined) } \\
\hline Male & $1.93 * *(0.67)$ & $2.50 *(1.21)$ & $1.64 * *(0.53)$ & $0.63(0.39)$ & $0.57 *(0.27)$ & $1.45 * * *(0.34)$ \\
\hline Female & $3.28 * * *(0.60)$ & $3.85 * *(1.24)$ & $2.98 * * *(0.60)$ & $1.96 * *(0.69)$ & $1.90 * *(0.60)$ & $2.79 * * *(0.49)$ \\
\hline \multicolumn{7}{|c|}{ Independent variable: maternal influence } \\
\hline Male & $0.55(0.73)$ & $1.34 *(0.62)$ & $0.36(0.29)$ & $0.17(0.09)$ & $0.18 *(0.08)$ & $0.52 * *(0.20)$ \\
\hline Female & $2.06 * * *(0.54)$ & $2.86^{* * *}(0.80)$ & $1.87 *(0.73)$ & $1.67 * * *(0.51)$ & $1.68 * * *(0.52)$ & $2.02 * * *(0.48)$ \\
\hline \multicolumn{7}{|c|}{ Independent variable: non-maternal influence } \\
\hline Male & $1.81 * *(0.69)$ & $2.45(1.32)$ & $1.63 * *(0.56)$ & $0.66(0.43)$ & $0.57 *(0.28)$ & $1.42 * * *(0.36)$ \\
\hline Female & $3.14 * * *(0.66)$ & $3.79 * *(1.30)$ & $2.96 * * *(0.68)$ & $1.98 *(0.79)$ & $1.89 * *(0.64)$ & $2.75 * * *(0.54)$ \\
\hline
\end{tabular}

Upper cell values represent \% change; lower cell values show robust standard error in parentheses

Orphans are excluded in this analysis. Asterisks indicate significance level: $* P \leq 0.05 ; * * P \leq 0.01 ; * * * P \leq 0.001$

technique of males and females of different ages. See the online supplement for graphs of the raw data (S2), and an alternative analysis of the amount of impact presented in Table 2 that includes orphans (S3, S4). For all three types of foraging neighbors, observed technique significantly predicted the practiced technique for females of all ages with females preferring the technique most frequently observed. However, social influence had somewhat weaker predictive power (in the same direction) for males' practiced techniques at all ages, attaining statistical significance only in some years. The impact was somewhat less for males when orphans were included in the sample, attaining significance only in the first year of life for overall and non-maternal influences: see S4 and S4. Figure 3 shows the impact of the observed technique for the practiced technique over time, for males and females (see S4 for graphs of results including orphans).

There was no significant statistical difference in the impact between any consecutive years, for either maternal or non-maternal influence on practiced technique. However, the impact of non-maternal influence in years 1-3 was significantly greater than the impact in years $4-5$ (coefficient 1.33, SE 0.61, $P=0.03$ ); no such difference in impact over time existed for the maternal influence.

In general, individuals with an early bias toward one technique continued to strengthen that bias as they aged (see S2). During their fifth year of development, both males and females were using their predominant technique unaccompanied by other techniques in $94.6 \%$ of their processing events (SD 9.2\%, $N=17$ ), and in about two-thirds of cases (10 of 15 cases for which data were available for both periods), the technique strongly preferred in year 5 was the one slightly preferred in the first 2 years. However, two males exhibited a bias toward scrubbing (the maternal technique) in years $1-3$, but then switched to pounding, the technique used by their male peers, in year 3 or 4 . Two offspring and two close associates of one adult female used her preferred aberrant and inefficient technique (pounding with the foot), but later settled on either scrubbing or normal pounding as the predominant technique (see S1).

\section{Sex differences}

Males and females did not differ significantly with regard to the amount of time they spent with their mothers or with regard to the amount of time they spent alone during any year (see Table 3 for details). Nor did they differ significantly with regard to the proportion of processing events in which they looked at neighboring foragers while processing Luehea (Table 4) or with regard to the proportion of times they visually oriented toward nearby foragers feeding on any food type (see Table 5). The one significant $P$ value ( $P=0.05$ for the 4- to 6-month-old sample) becomes nonsignificant when Bonferroni corrections are applied.

Conformity to maternal technique

Using data on the most recent available Luehea-processing season from all individuals of all ages whose maternity was known $(N=106)$, subjects were significantly likely to use the same technique as their mothers (Fisher's exact, $P=0.001)$. This result was significant for the 48 females considered alone $(P=0.002)$, but not for the 58 males $(P=0.18)$.

\section{Discussion}

Advantages of using a longitudinal study design in capuchins for investigating social learning

With the noteworthy exception of the early Japanese macaque research (Itani and Nishimura 1973), most research seeking to demonstrate social influence on food 

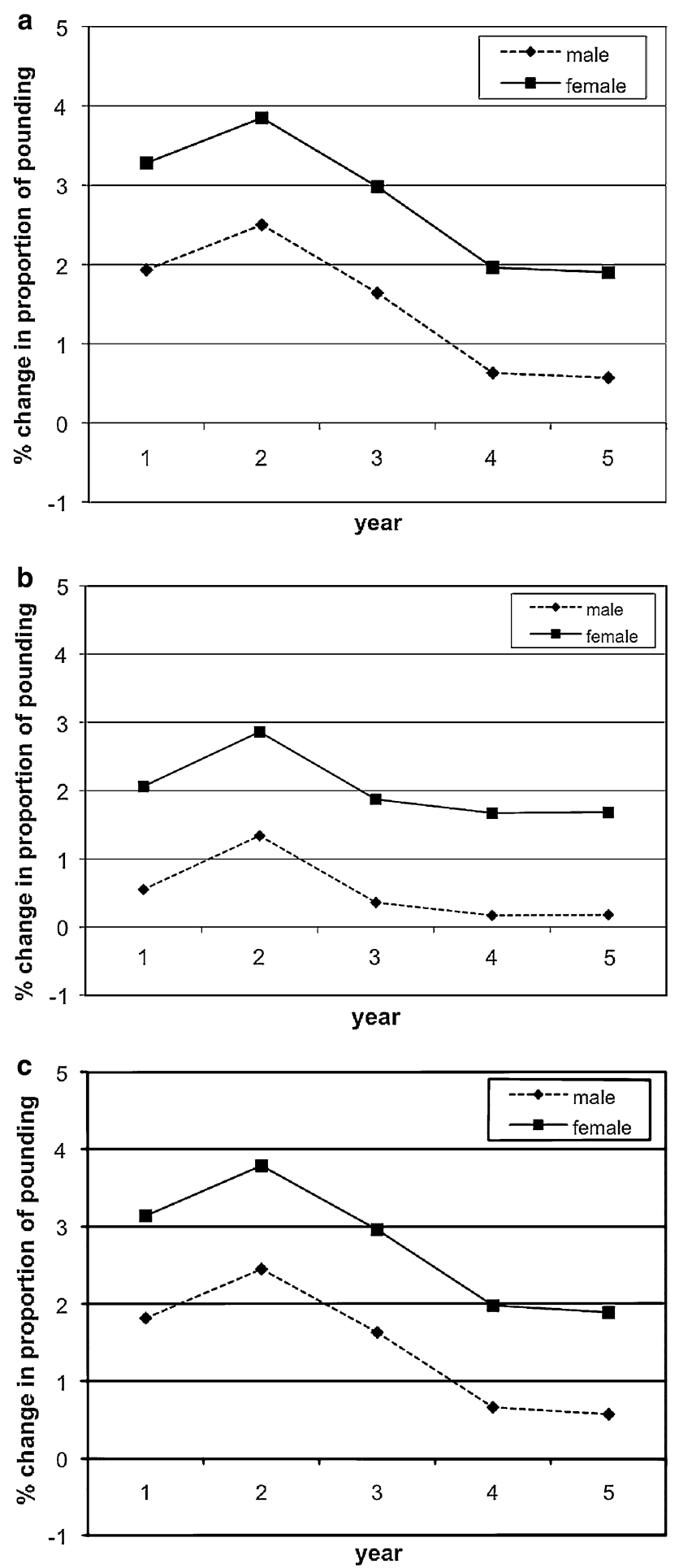

Fig. 3 Graphs of impact of observed technique on practiced technique. Orphans are not included in this analysis. $Y$-axis is " $\%$ change in proportion of pounding practiced" resulting from a $1 \%$ change in observed technique. a Impact of social influence (maternal and nonmaternal); $\mathbf{b}$ impact of maternal influence, and $\mathbf{c}$ impact of non-maternal influence

processing techniques in wild primate populations has employed either the group contrasts approach or a developmental approach in ape species that have semi-solitary and/ or fission fusion social structures. In the case of the group contrasts studies (Whiten et al. 1999; van Schaik et al. 2003a), social influence was assumed when the researchers deemed it improbable that the patterning of traditions between sites was due to genetic or ecological factors. Also, the amount of time spent associating with non-dependent conspecifics was correlated with the number of traditions at a site, under the assumption that having greater exposure to models would enhance the efficacy of social learning (van Schaik 2003; van Schaik et al. 2003a, b). However, the behavioral practices and association patterns of individual animals were not presented in these studies. Therefore, it was impossible to make strong inferences in these studies about which individuals were transmitting practices to which other individuals, the ages at which behavioral practices are most likely to be socially influenced, or the circumstances that make social transmission more or less likely to occur.

Longitudinal developmental studies, if properly conducted, can provide a richer source of insight into the behavioral processes affecting the acquisition of behaviors than is possible in the group contrast studies or in shortterm cross-sectional studies of the distribution of behavioral traits. Primate species differ widely in their social structures, so that there is much variation in the amount of exposure that individuals have to group members of various age-sex classes within groups, the amount of home range overlap between individuals in a community, and the amount of contact between social groups.

The difference between the social structures of capuchin monkeys and those of chimpanzees and orangutans (the two ape species for which there are developmental data in free-ranging animals) affords both advantages and disadvantages for evaluating the role of social influence. Because capuchins travel as large, cohesive groups, it is possible to collect data on a much larger sample of individuals than is possible for studies of apes, but it is also more difficult to disentangle the sources of social influence in a group size of 37 capuchins, compared to a typical foraging party size of two orangutans (van Schaik et al. 2003b) or 5-6 chimpanzees (Newton-Fisher et al. 2000) who regularly associate. While it is impossible to say which individual animals were the primary models [i.e,. the model(s) having the most influence, regardless of time spent in proximity] for any particular capuchin monkey, it is possible at least to measure the level of exposure to each model and to identify which techniques were observed most often. A major advantage of the capuchin research setting, compared to the chimpanzee or orangutan setting, is that capuchins forage cohesively when eating fruit, visiting the same trees simultaneously (Fragaszy et al. 2004), whereas subjects within a particular orangutan or chimpanzee community may have quite different core areas and do not often visit the same 
Table 3 Between-sex comparison of the percentage of time focal monkeys spent in proximity

\begin{tabular}{|c|c|c|c|c|c|c|}
\hline & \multicolumn{3}{|c|}{$\%$ Time spent with mother* } & \multicolumn{3}{|c|}{$\%$ Time spent alone** } \\
\hline & Female mean & Male mean & $P$ value & Female mean & Male mean & $P$ value \\
\hline Year 1 & $8.1(2)$ & $14.8(2)$ & 0.33 & $11.5(2)$ & $6.9(2)$ & 0.32 \\
\hline Year 2 & $3.3(5)$ & $5.7(6)$ & 0.14 & $24.3(5)$ & $18.3(6)$ & 0.14 \\
\hline Year 3 & $3.5(9)$ & $1.8(12)$ & 0.16 & $28.2(9)$ & $22.6(12)$ & 0.12 \\
\hline Year 4 & $2.7(5)$ & $2.3(7)$ & 0.75 & $22.9(5)$ & $24.3(7)$ & 0.56 \\
\hline Year 5 & $4.8(5)$ & $1.4(4)$ & 0.20 & $29.5(5)$ & $23.0(4)$ & 0.23 \\
\hline
\end{tabular}

Sample sizes are in parentheses

*Within one body length $(40 \mathrm{~cm})$ of the mother

**With no other monkey within ten body lengths $(400 \mathrm{~cm})$

Table 4 Percentage of Luehea foraging bouts in which the forager looked at other Luehea foragers within a radius of $400 \mathrm{~cm}$

\begin{tabular}{llll}
\hline $\begin{array}{l}\text { Age } \\
\text { (years) }\end{array}$ & $\begin{array}{l}\text { Female } \\
\text { mean }(N)\end{array}$ & $\begin{array}{l}\text { Male } \\
\text { mean }(N)\end{array}$ & $\begin{array}{l}P \text { value } \\
\text { (two-tailed) }\end{array}$ \\
\hline 1 & $9.7(2)$ & $8.8(2)$ & 0.98 \\
2 & $11.7(6)$ & $9.5(11)$ & 0.65 \\
3 & $5.7(12)$ & $11.0(16)$ & 0.14 \\
4 & $4.3(8)$ & $6.7(8)$ & 0.39 \\
5 & $8.9(8)$ & $9.6(6)$ & 0.84 \\
\hline
\end{tabular}

Number of individuals is in parentheses

feeding sites during the same time periods. Even capuchin monkeys residing in adjacent social groups visit the same fruiting trees, though never at the same time. So, it can safely be assumed that the different monkeys in the same population are not adopting different foraging techniques because of subtle ecological differences in the quality of the fruits.

Interpretation of the results

Even though the regression model presented in this paper indicates that observed technique (i.e., the technique to which the animal has the greatest exposure due to spatial relations during foraging) predicts the technique practiced, these data are observational rather than experimental, and it is of course possible that the two variables are not causally related, but merely correlated. However, several additional observations lend credence to the argument that this is likely to be a causal relationship rather than a statistical artifact. Here, I will consider whether the reverse causality is plausible, and also consider whether some third unmeasured factor is likely to explain the association between observed and practiced techniques.

The reverse prediction would be that the practiced technique has an effect on what the animals have an opportunity to observe. One way that such a situation might arise is for animals to identify with those who behave similarly to
Table 5 Comparison of males and females with regard to the percentage of foraging bouts by neighbors within $200 \mathrm{~cm}$ to which they visually attended

\begin{tabular}{|c|c|c|c|}
\hline $\begin{array}{l}\text { Age } \\
\text { (months) }\end{array}$ & $\begin{array}{l}\text { Female } \\
\text { mean }(N)\end{array}$ & $\begin{array}{l}\text { Male } \\
\text { mean }(N)\end{array}$ & $\begin{array}{l}P \text { value } \\
\text { (two-tailed) }\end{array}$ \\
\hline $0-3$ & $27(3)$ & $15(2)$ & 0.99 \\
\hline $4-6$ & $36(5)$ & $50(4)$ & 0.05 \\
\hline $7-9$ & 47 (9) & 49 (4) & 0.86 \\
\hline $10-12$ & $47(8)$ & $45(6)$ & 0.84 \\
\hline $13-15$ & $42(7)$ & $54(4)$ & 0.14 \\
\hline $16-18$ & $46(9)$ & $51(6)$ & 0.56 \\
\hline $19-21$ & $41(12)$ & $40(7)$ & 0.85 \\
\hline $22-24$ & $40(10)$ & $43(8)$ & 0.61 \\
\hline $25-27$ & $43(10)$ & $37(8)$ & 0.32 \\
\hline $28-30$ & $39(9)$ & $43(10)$ & 0.46 \\
\hline $31-33$ & $41(12)$ & 39 (10) & 0.60 \\
\hline $34-36$ & $48(10)$ & $43(9)$ & 0.32 \\
\hline $37-39$ & 37 (8) & $42(7)$ & 0.30 \\
\hline $40-42$ & $39(8)$ & $42(7)$ & 0.76 \\
\hline $42-45$ & $43(7)$ & $43(7)$ & 0.96 \\
\hline $46-48$ & $39(5)$ & $49(5)$ & 0.37 \\
\hline $49-51$ & $43(4)$ & $43(4)$ & 0.97 \\
\hline $52-54$ & $40(5)$ & $45(4)$ & 0.43 \\
\hline $55-57$ & $42(5)$ & $58(2)$ & 0.20 \\
\hline $58-60$ & $49(2)$ & $66(2)$ & 0.66 \\
\hline
\end{tabular}

$N$ (the number of focal individuals) is in parentheses

themselves and then sort themselves spatially to preferentially associate with similar-acting animals. However, given that there are so many dimensions along which dyads can be similar or dissimilar, including many variants of social communicative behavior (Perry and Manson 2008) that are linked to the alliance structure of the group, it seems implausible that the monkeys would sort themselves spatially according to the preference for a particular foodprocessing technique. Also, the fact that social learning of food processing behaviors has been documented in captive studies of many species including capuchins (Fragaszy 
et al. 2004; Dindo et al. 2007) lends plausibility to the interpretation that observation of others' foraging techniques can influence which techniques are used.

Third variables that are commonly considered likely to affect both observed and practiced techniques are (a) genetic similarity, and (b) ecological factors promoting similar trial-and-error learning responses in individuals. It is impossible to completely rule out the possibility that genetic factors make individual monkeys show a slight propensity toward adopting one of the two techniques. However, all individuals in the sample are certainly capable of executing both techniques and $85 \%$ of individuals use both techniques during the first 2 years of life. It seems highly unlikely that individual genetically based biases could explain the statistically significant observed pattern, in which individuals end up adopting the technique they see performed most often. In order for genetic differences to explain such a pattern, we would have to assume that individuals bearing the genes biasing them toward the use of a particular technique also preferentially associate with one another in foraging contexts. The most plausible way in which this could occur is if individuals preferentially foraged with their primary kin. However, in fact, young capuchins begin to associate preferentially with peers quite early in life. Only $7 \%$ of 1 - and 2-year-old individuals in my sample for whom parentage was known and for which there was sufficient behavioral data $(N=14)$ had a parent as one of their top three associates during Luehea processing, and on average, only 0.9 of their top three associates was related at a level of $r \geq 0.25$, despite the fact that capuchins typically have many siblings in the group in this population (Perry et al. 2008). Of these 14 individuals, three had a same-sexed adult as the nearest neighbor during foraging and the other 11 had a same-sexed juvenile as the nearest neighbor (three of which were paternal half-siblings).

The second class of variables that might cause a non-causal correlation between observed and practiced technique is ecological variables affecting the efficacy of different processing techniques. It could be hypothesized that subtle differences in the properties of fruits might make scrubbing more effective in some fruits, and pounding more effective in other fruits, so that animals who foraged together more often might encounter fruits with the same properties, resulting in similarities in style among frequent associates due to similar feedback that these individuals received in trial-and-error learning. This sort of hypothesis can be discounted in the current data set for two reasons. First, no significant difference in effectiveness of technique was found between pounding and scrubbing that could bias independent learning toward a particular outcome via operant conditioning. Second, there was no difference in the exposure of pounders versus scrubbers toward particular patches of Luehea that could provide differential experience between these two classes of foragers. Pounders and scrubbers of the same group visited the same Luehea trees at the same time, and there was also extensive overlap in the usage of these feeding sites between adjacent groups of monkeys.

The findings that (1) individuals do not settle into their final technique until around year 5 (or, at least, do not stop using the non-preferred technique till then), and (2) most individuals handle over 1,000 Luehea fruits per year of life, indicate that capuchins require a large amount of social exposure and experience before they systematically prefer the technique observed most. It is possible, of course, that social influence has more or less impact, and operates on a different time scale, for tasks in which there is more of a difference in feeding return for alternative techniques, or for skills that are more difficult to acquire by individual learning. The lack of a sharp drop-off in the impact of observed technique on practiced technique from one year to the next over the 5-year period suggests that there is no sharply defined critical period when social influence affects choice of the Luehea processing technique that will be preferred in adulthood. However, earlier exposure (years 1-3) does seem to be slightly more important than later exposure.

\section{Comparison with other studies of conformity:} sex differences and comparative perspectives

The sex difference in the influence of social exposure is puzzling. Similar results in chimpanzees (Lonsdorf et al. 2004) have been explained not by the amount of exposure to maternal techniques, but rather by the relative attentiveness of males and females. In this study neither time spent in proximity nor visual attentiveness to foraging monkeys explains the sex difference in tendency to conform. De Waal's (2001) "Bonding- and Identification-based Observational Learning Model" suggests that individuals obtain an intrinsic pleasure from copying the actions of individuals with whom they have special bonds (such as the mother or close companions), even when there is no advantage of copying the particular behavioral variant in question. It could be, then, that these philopatric female capuchins are more motivated than males are to identify with groupmates, and particularly with their mothers and other female kin, and hence are more influenced by what they observe others do. It might be expected that male capuchins would identify more with other males than with females and hence would be more prone to copying males than females are. The analyses presented here do not clearly address the issue of which sex model is most influential to males as opposed to females, but this would be an interesting topic for future research.

Conformity biases have been documented in a number of taxa, though the word is not used in quite the same way in all studies. For example, guppies follow the group majority when seeking foraging routes (Day et al. 2001). 
Recently, Whiten and van Schaik (2007) have made the claim that although conformity in the sense of "following the majority" may be widespread taxonomically, chimpanzees and humans are unique in that they converge on the behavioral variant that is most common in the group, even if they have alternative behaviors in their individual repertoires that accomplish the same goal just as efficiently. The capuchin data presented here, as well as recent data on Norway rat food choices (in which rats ignored previous knowledge about what foods were toxic or unpalatable in order to eat what they saw a model eat: Galef and Whiskin 2008) show that other species may also let a desire to conform to what they have seen override individually attained knowledge. The finding that social cues are often used even when alternative reliable sources of information are present is fascinating, and clearly more research is needed to determine the range of circumstances that cause animals to conform.

Acknowledgments I would like to thank the following field assistants for contributing observations to this data set: J.C. Ordoñez J., W. Lammers, C. Carlson, H. Gilkenson, M. Kay, A. Fuentes J., C. Gault, S. Herbert, K. Feilen, C. Mitchell, M. Milstein, G. Dower, D. Kerhoas-Essens, L. Johnson, S. Hyde, E. Kennedy, S. Kessler, F. Campos, A. Bjorkman, I. Godoy, N. Donati, J. Vandermeer, H. Ruffler, L. Beaudrot, J. Broesch, M. Bergstrom, J. Butler, W. Meno, K. Potter, J. Williams, T. Lord, C. Schmitt, N. Parker, K. Ratliff, and B. Pav. I am particularly grateful to H. Gilkenson and W. Lammers for managing the field site. This project is based on work supported by the Max Planck Institute for Evolutionary Anthropology, The WennerGren Foundation, the National Geographic Society, the National Science Foundation (grant No. 0613226), and the L.S.B. Leakey Foundation. X. Chen and P. Ender of the ATS statistical consulting lab at UCLA assisted with the analysis. E. Wikberg and W. Lammers helped to compile the data. I thank the Costa Rican park service (MINAE), the Area de Conservacion Tempisque-Arenal, Hacienda Pelon de la Bajura, Hacienda Brin D'Amour, and the residents of San Ramon de Bagaces for permission to work on their land. J. Manson, J. Silk, $\mathrm{X}$. Chen and three anonymous reviewers provided helpful comments on the manuscript. This research was performed in compliance with the laws of Costa Rica, and the protocol was approved by the UCLA animal care committee (ARC\#2005-084).

Open Access This article is distributed under the terms of the Creative Commons Attribution Noncommercial License which permits any noncommercial use, distribution, and reproduction in any medium, provided the original author(s) and source are credited.

\section{References}

Bonnie KE, de Waal FBM (2007) Copying without rewards: socially influenced foraging decisions among brown capuchin monkeys. Anim Cogn 10:283-292

Box H (1984) Primate behaviour and social ecology. Chapman \& Hall, London

Byrne RW (2007) Culture in great apes: using intricate complexity in feeding skills to trace the evolutionary origin of human technical prowess. Phil Trans R Soc B 362:577-585
Corp N, Byrne RW (2002) The ontogeny of manual skill in wild chimpanzees: evidence from feeding on the fruit of Saba florida. Behaviour 139:137-168

Day RL, Macdonald R, Brown C, Laland KN, Reader SM (2001) Interactions between shoal size and conformity in guppy social foraging. Anim Behav 62:917-925

de Waal FBM (2001) The ape and the Sushi-Master: cultural reflections of a primatologist. Harvard University Press, Cambridge

De Waal FBM, Bonnie KE (2009) In tune with others: the social side of culture. In: Laland K, Galef BG (eds) The question of animal culture. Harvard University Press, Cambridge, pp 19-40

Dindo M, Thierry B, Whiten A (2007) Social diffusion of novel foraging methods in brown capuchin monkeys (Cebus apella). Proc $\mathrm{R}$ Soc B 275:187-193

Fragaszy D, Perry S (2003) Towards a biology of traditions. In: Fragaszy D, Perry S (eds) The biology of traditions: models and evidence. Cambridge University Press, Cambridge, pp 1-32

Fragaszy D, Visalberghi E, Fedigan LM (2004) The complete capuchin: the biology of the genus Cebus. Cambridge University Press, Cambridge

Fredman T, Whiten A (2008) Observational learning from tool using models by human-reared and mother-reared capuchin monkeys (Cebus apella). Anim Cogn 11:295-309

Galef BG, Whiskin EE (2008) 'Conformity' in Norway rats? Anim Behav 75:2035-2039

Huffman MA, Hirata S (2004) An experimental study of leaf swallowing in captive chimpanzees: insights into the origin of a self-medicative behavior and the role of social learning. Primates 45:113118

Itani J, Nishimura A (1973) The study of infrahuman culture in Japan: A review. Symposium of the IVth International Congress of Primatology: precultural primate behavior, vol 1, Basel, Karger, pp 26-50

Kenward B, Rutz C, Weir AAS, Kacelnik A (2006) Development of tool use in New Caledonian crows: inherited action patterns and social influences. Anim Behav 72:1329-1343. doi:10.1016/j.anbehav.2006.04.007

Kummer H (1995) In quest of the sacred baboon: a scientist's journey. Princeton University Press, Princeton

Laland K, Galef BG (eds) (2009) The question of animal culture. Harvard University Press, Cambridge

Long JS, Freese F (2006) Chapter 8: models for count outcomes. In: Regression models for categorical dependent variables using Stata, 2nd edn. Stata Press, College Station

Lonsdorf E, Eberly LE, Pusey AE (2004) Sex differences in learning in chimpanzees. Nature 428:715-716

Muniz L, Perry S, Manson J, Gilkenson H, Gros-Louis J, Vigilant L (2006) Father-daughter inbreeding avoidance in a wild primate population. Curr Biol 16:156-157

Newton-Fisher NE, Reynolds V, Plumptre AJ (2000) Food supply and chimpanzee (Pan troglodytes schweinfurthii) party size in the Budongo Forest Reserve, Uganda. Int J Primatol 21:613-628

O'Malley RC, Fedigan LM (2005) Evaluating social influences on food processing behavior in white-faced capuchins (Cebus capucinus). Am J Phys Anthropol 127:481-491

Panger M, Perry S, Rose L, Gros-Louis J, Vogel E, MacKinnon K, Baker M (2002) Cross-site differences in the foraging behavior of white-faced capuchin monkeys (Cebus capucinus). Am J Phys Anthropol 119:52-66

Perry S (2006) What cultural primatology can tell anthropologists about the evolution of culture. Ann Rev Anthropol 35:171-190

Perry S (2009) Are nonhuman primates likely to exhibit cultural capacities like those of humans? In: Laland K, Galef BG (eds) The question of animal culture. Harvard University Press, Cambridge, pp 247-268 
Perry S, Manson JH (2003) Traditions in monkeys. Evol Anthropol 12:71-81

Perry S, Manson JH (2008) Manipulative monkeys: the capuchins of Lomas Barbudal. Harvard University Press, Cambridge

Perry S, Ordoñez Jiménez JC (2006) The effects of food size, rarity, and processing complexity on white-faced capuchins' visual attention to foraging conspecifics. In: Hohmann G, Robbins M, Boesch C (eds) Feeding ecology in apes and other primates. Cambridge University Press, Cambridge, pp 203-234

Perry S, Manson J, Muniz L, Gros-Louis J, Vigilant L (2008) Kin-biased social behaviour in wild adult female white-faced capuchins (Cebus capucinus). Anim Behav 76:187-199

Richerson PJ, Boyd R (2005) Not by genes alone: how culture transformed human evolution. The Chicago University Press, Chicago

Russon A (2003) Developmental perspectives on great ape traditions. In: Fragaszy D, Perry S (eds) The biology of traditions: models and evidence. Cambridge University Press, Cambridge, pp 329364

Russon AE, Handayani DP, Kuncoro P, Ferisa A (2007) Orangután leaf-carrying for nest-building: Towards unraveling cultural processes. Anim Cogn 10:189-202
Snowdon CT (2001) From primate communication to human language. In: de Waal FBM (ed) Tree of origin: what primate behavior can tell us about human social evolution. Harvard University Press, Cambridge, pp 193-228

van Schaik CP (2003) Local traditions in orangutans and chimpanzees: social learning and social tolerance. In: Fragaszy D, Perry S (eds) The biology of traditions: models and evidence. Cambridge University Press, Cambridge, pp 297-328

van Schaik CP, Ancrenaz M, Borgen W, Galdikas B, Knott CD, Singleton I, Suzuki A, Utami SS, Merrill M (2003a) Orangutan cultures and the evolution of material culture. Science 299:102-105

van Schaik CP, Fox EA, Fechtman LT (2003b) Individual variation in the rate of use of tree-hole tools among wild orangutans: implications for hominin evolution. J Hum Evol 44:11-23

Whiten A, van Schaik CP (2007) The evolution of animal 'cultures' and social intelligence. Phil Trans R Soc B 362:603-620

Whiten A, Goodall J, McGrew WC, Nishida T, Reynolds V, Sugiyama Y, Tutin CEG, Wrangham RW, Boesch C (1999) Cultures in chimpanzees. Nature 399:682-685

Whiten A, Horner V, de Waal FBM (2005) Conformity to cultural norms of tool use in chimpanzees. Nature 437:737-740 